\title{
INOVASI MODEL QUANTUM LEARNING MENGGUNAKAN TEORI APERSEPSI BERBASIS KARAKTER UNTUK MENINGKATKAN KUALITAS PEMBELAJARAN MATAKULIAH PENDIDIKAN IPS SD
}

Fitria Dwi Prasetyaningtyas

Universitas Negeri Semarang

E-mail: fitriadwiprasetyaningtyas02@gmail.com

\begin{abstract}
Abstrak: Tujuan dari penelitian adalah menghasilkan inovasi model pembelajaran dengan mengembangkan model pembelajaran quantum learning berbasis karakter untuk meningkatkan kualitas pembelajaran IPS SD. Penelitian ini adalah campuran antara penelitian kulaitatif dan kuantitatif. Penelitian kualitatif dipilih untuk mendeskripsikan penerapan model quantum learning menggunakan teori apersepsi berbasis karakter untuk meningkatkan kualitas pembelajaran matakuliah pendidikan IPS SD. Penelitian kuantitatif yang berupa pre eksperimental design yaitu one-group pretest-postest design, untuk melihat pemahaman mahasiswa sebelum dan sesudah penerapan model. Pengembangan model menggunakan desain pembelajaran ADDIE. Simpulan penelitian adalah 1) pengembangan model quantum learning menggunakan teori apersepsi berbasis karakter menggunakan tahapan TANDUR (Tumbuhkan, Alami, Namai, Demonstrasikan, Ulangi dan Rayakan) dimana dalam tahapan memiliki alokasi waktu yang berbeda-beda, 2) kelayakan model quantum learning menggunakan teori apersepsi berbasis karakter pada kategori sangat layak untuk diuji cobakan dengan data jumlah skor 15 dengan nilai rata-rata 90 dan persentase sebanyak 93,75\%,3) model quantum learning menggunakan teori apersepsi mata kuliah pendidikan IPS SD dapat menumbuhkan karakter mahasiswa karakter inspiratif mahasiswa sudah terlihat melalui kegiatan pengamatan, dengan jumlah skor 8,82 dengan rata-rata skor 2,94 pada kategori mulai berkembang. Saran dari penelitian ini adalah pelaksanaan model kedepannya diharapkan perlu untuk merencanakan setiap kegiatan pembelajaran dan alokasi waktu pembelajaran dengan baik serta menggunakan media pembelajaran yang relevan agar semua tahapan bisa dilaksanakan.
\end{abstract}

\section{Kata kunci: Model Quantum Learning, Teori Apersepsi, Karakter, IPS}

\begin{abstract}
The aim of the research is to produce innovative learning models by developing character-based quantum learning models to improve the quality of elementary social studies learning. This research is a mixture of qualitative and quantitative research. Qualitative research was chosen to describe the application of quantum learning models using character-based apperception theory to improve the quality of learning in social studies elementary school subjects. Quantitative research in the form of pre experimental design is one-group pretest-posttest design, to see student understanding before and after applying the model. Model development using ADDIE learning design. The conclusions of the research are 1) the development of quantum learning models using characterbased apperception theory using the TANDUR (Grow, Natural, Named, Demonstrate, Repeat and Celebrate) stages where the stages have different time allocations, 2) the feasibility of the quantum learning model using apperception theory character-based in the category is very feasible to try with data on the number of scores of 15 with an average value of 90 and a percentage of $93.75 \%$, 3) quantum learning models using apperception theory of elementary school IPS education courses can foster the character of students inspirational characters of students already seen through observation, with a total score of 8.82 with an average score of 2.94 in the category began to develop. Suggestions from this research are the future implementation of the model is expected to need to plan
\end{abstract}


each learning activity and allocation of learning time properly and use relevant learning media so that all stages can be carried out.

Keywords: Quantum Learning Model, Apperception Theory, Characters, Social Sciences

Submitted on: 2019-04-26

Accepted on: 2019-07-29

\section{PENDAHULUAN}

Pendidikan nasional berfungsi mengembangkan kemampuan dan membentuk watak serta peradaban bangsa yang bermartabat dalam rangka mencerdasakan kehidupan bangsa, bertujuan untuk berkembangnya potensi peserta didik agar menjadi manusia yang beriman dan bertaqwa kepada Tuhan yang Maha Esa, berakhlak mulia, sehat, berilmu, cakap, kreatif, mandiri, dan menjadi warga Negara yang demokratis serta bertanggung jawab salah satunya adalalah melalui pembelajaran IPS (Sisdiknas, 2003:2-4). Sementara itu, matakuliah Pendidkan IPS SD merupakan mata kuliah yang diharapkan dapat mengantarkan mahasiswa untuk mencapai kompetensi menguasai substansi dan metodologi dasar keilmuan IPS, menguasai materi ajar dalam kurikulum dan buku teks IPS $\mathrm{SD}$, menguasai prinsip-prinsip dasar yang mendidik.

Namun ada beberapa kendala yang menyebabkan pembelajaran IPS belum optimal sehingga kualitas pembelajaran menjadi belum maksimal pula. Salah satunya adalah karena dalam pembelajaran kurang mengoptimalkan pembelajaran inovatif dan kreatif. Oleh karena itu, peneliti melakukan kegiatan pengembangan model pembelajaran dan mengkaji lebih lanjut dalam penelitian dengan judul "Inovasi Model Quantum Learning Menggunakan Teori Apersepsi Berbasis Karakter untuk Meningkatkan Kualitas Pembelajaran IPS SD”. Adapun masalah dalam penelitian ini yaitu 1) bagaimana pengembangan model quantum learning menggunakan teori apersepsi berbasis karakter, 2) bagaimana kelayakan model quantum learning menggunakan teori apersepsi berbasis karakter, dan 3) apakah model quantum learning menggunakan teori apersepsi mata kuliah pendidikan ips sd dapat menumbuhkan karakter mahasiswa.

\section{METODE PENELITIAN}

Pengembangan model pembelajaran dalam penelitian ini adalah model desain pembelajaran ADDIE (Analysis, Design, Develop, Implemen, Evaluation), model ini dikembangkan oleh Reiser dan Morella (Pargito, 2010:46). Penelitian ini dirancang melalui studi pendahuluan dengan pendekatan deskriptif kualitatif, kemudian dilanjutkan tahap 


\section{ELSE (Elementary Schod Education Journal) \\ Volume 3 Nomor 2 Agustus 2019 \\ P-ISSN: 2581-1800 E-ISSN: 2597-4122 \\ Email: else@um-surabaya.ac.id}

pengembangan yang dimulai dengan perancangan inovasi model pembelajaran, validasi desain, perbaikan desain, uji coba model, revisi model, dan pengembangan model final.

Teknik pengumpulan data menggunakan observasi dan studi dokumen. Teknik ini digunakan untuk melihat potensi dan masalah yang ada, kemudian pada saat studi pengembangan menggunakan desain model, pada saat uji coba terbatas menggunakan rancangan teknis model dan angket yang digunakan untuk dan mengukur keberhasilan model. Sedangkan teknik analisis data yang digunakan yaitu analisis model berjenjang. Teknik analisis ini dilakukan untuk menghasilkan model final yang sesuai dengan target yang direncanakan.

\section{HASIL DAN PEMBAHASAN}

Pengembangan Model Quantum Learning Menggunakan Teori Apersepsi Berbasis Karakter

Pada tahap pengembangan model quantum learning menggunakan teori apersepsi berbasis karakter penilaian rancangan pengembangan model dilakukan oleh ahli pembelajaran dengan menggunakan instrumen validasi penilaian. Proses pengembangan menggunakan tahapan TANDUR (Tumbuhkan, Alami, Namai, Demonstrasikan, Ulangi dan Rayakan) dimana dalam tahapan memiliki alokasi waktu yang berbeda-beda (De Potter, 2010). Adapun hasil penembangan model adalah sebagai berikut.

\section{Tabel 1. Pengembangan Model Quantum Learning Menggunakan Teori Apersepi}

\begin{tabular}{|c|c|}
\hline Kegiatan & Langkah-Langkah Kegiatan (10 menit) \\
\hline Pendahuluan & $\begin{array}{l}\text { Pra kegiatan } \\
\text { 1. Menyampaikan ucapan salam } \\
\text { 2. Menciptakan kondisi kelas } \\
\text { 3. Menjelaskan kompetensi yang ingin dicapai } \\
\text { 4. Menjelaskan manfaat bahan pembelajaran } \\
\text { 5. Menghubungkan bahan kajian dengan materi sebelumnya } \\
\text { 6. Menggali pengalaman belajar dan pengetahuan awal berkenaan dengan } \\
\text { 7. Mengkup materi yang akan dikaji } \\
\text { 7. Man sarana yang diperlukan }\end{array}$ \\
\hline Inti & $\begin{array}{l}\text { TUMBUHKAN (15 menit) } \\
\text { Apersepsi } \\
\text { 1. Dosen mengajak mahasiswa membentuk kelompok. Tiap kelompok } \\
\text { terdiri dari 5-6 anak dengan satu ketua kelompok. Kelompok membuat } \\
\text { nama kelompok menggunakan nama-nama negara di dunia. } \\
\text { 2. Dosen melakukan apersepsi AMBAK (apa manfaatnya bagiku) untuk } \\
\text { masuk ke materi baru. } \\
\text { 3. Mahasiswa ditunjukan gambar- gambar masalah social yang terjadi di } \\
\text { Indonesia (mengamati). } \\
\text { 4. Dosen dan mahasiswa melakukan tanya jawab tentang gambar tersebut } \\
\text { (menanya). }\end{array}$ \\
\hline
\end{tabular}


ALAMI (10 menit)

5. Guru membagikan lembar kerja kepada tiap kelompok.

NAMAI (20 menit)

6. Dosen bersama mahasiswa membahas lembar kerja.

7. Dosen memberi apersepsi scene setting menggunakan asas penyampaian berita atau informasi.

8. Dosen mengajak mahasiswa menonton video tentang masalah- masalah sosial di lingkungan lokal, nasional dan global

9. Dosen menjelaskan materi menggunakan media peta pikiran (menalar). DEMONSTRASIKAN (25 menit)

10. Dosen menawarkan kepada kelompok yang ingin maju untuk mendemonstrasikan pemecahan masalah-masalah sosial yang telah dipelajari bersama.

11. Setelah kelompok melakukan demonstrasi, kelompok lain memberikan apresiasi yang baik.

12. Dosen memberi reward kepada kelompok yang maju dan memberi pujian positif pada kelompok lain

13. Dosen menjelaskan tujuan dari demonstrasi tersebut.

14. Dosen memberikan evaluasi

Penutup

ULANGI (10 menit)

1. Dosen bersama mahasiswa merefleksi pembelajaran yang telah berlangsung.

RAYAKAN (10 menit)

2. Dosen bersama mahasiswa merayakan pembelajaran yang telah berlangsung.

3. Bersama-sama membuat simpulan dan ringkasan dari kegiatanyang telah dilaksanakan

4. Menutup perkuliahan dengan berdoa untuk menumbuhkan sikap religius.

Kelayakan Model Quantum Learning Menggunakan Teori Apersepsi Berbasis Karakter

Berdasarkan penilaian kelayakan dari ahli, model quantum learning dengan teori apersepsi termasuk dalam kategori sangat layak untuk diterapkan dengan jumlah skor 14 dengan nilai rata-rata 90 dan persentase sebanyak 87,5\% karena dalam pembelajaran dengan model ini dapat tercipta interaksi-interaksi yang dapat mengubah suasana belajar yang menyenangkan serta mengubah kemampuan dan bakat alamiah siswa menjadi cahaya yang akan bermanfaat bagi mereka sendiri dan bagi orang lain. Model Quantum Learning menggunakan teori apersepsi mata kuliah Pendidikan IPS SD dapat menumbuhkan karakter mahasiswa dalam kegiatan penelitian model Quantum Learning menggunakan teori apersepsi berbasis karakter, karakter inspiratif mahasiswa sudah terlihat melalui kegiatan pengamatan. Hal tersebut terlihat dari tabel berikut. 


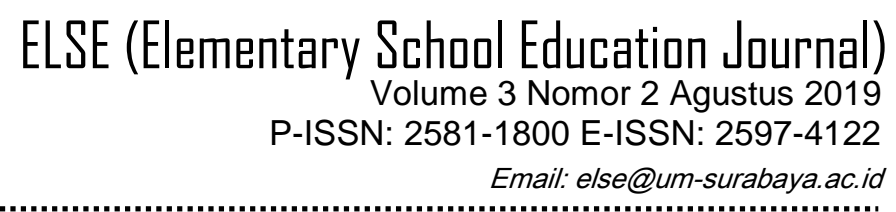

Tabel 2. Hasil Pengamatan Karakter

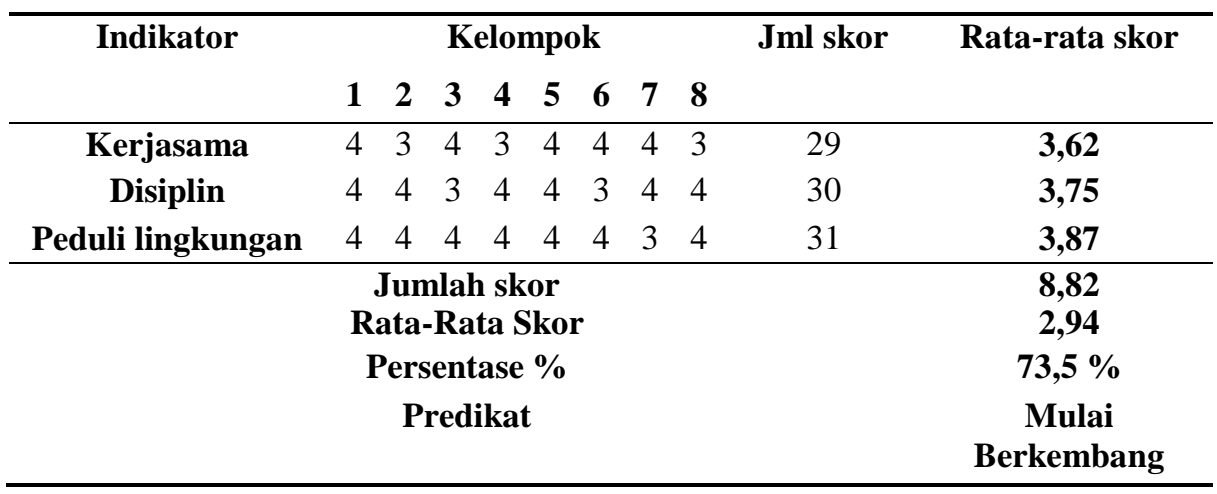

Dari data tersebut dapat dilihat jumlah skor 8,82 dengan rata-rata skor 2,94 pada kategori mulai berkembang. Indikator kerjasama mendapat skor rata-rata 3,6, sedangkan indicator disiplin menapat skor rata-rata 3,75 dan indikator peduli lingkungan mendapat skor 3,87 .

\section{KESIMPULAN DAN SARAN}

Proses pengembangan menggunakan tahapan TANDUR (Tumbuhkan, Alami, Namai, Demonstrasikan, Ulangi dan Rayakan) dimana dalam tahapan memiliki alokasi waktu yang berbeda-beda. Berdasarkan penilaian kelayakan dari ahli, model quantum learning dengan teori apersepsi termasuk dalam kategori sangat layak untuk diterapkan dengan data jumlah skor 15 dengan nilai rata-rata 90 dan persentase sebanyak $93,75 \%$ pada kategori sangat layak untuk diuji cobakan. Karakter inspiratif mahasiswa sudah terlihat melalui kegiatan pengamatan, dengan jumlah skor 8,82 dengan rata-rata skor 2,94 pada kategori mulai berkembang.

\section{DAFTAR PUSTAKA}

BSNP. 2006. Permendiknas Nomor 22 Tahun 2006 tentang Standar Isi. Jakarta: CV.Mini Jaya Abadi.

De Porter, Bobbi dan Mike Hernacki. 2013. Quantum Learning: Membiasakan Belajar Nyaman dan Menyenangkan. Terjemahan Alwiyah Abdurrahman. Bandung: Kaifa.

De Porter, Bobbi. Dkk. 2010. Quantum Teaching: Mempraktikan Quantum Leraning di Ruang-ruang Kelas. Terjemahan Nilandri. Bandung: Kaifa. 
Susanto, Ahmad. 2014. Teori Belajar dan Pembelajaran di Sekolah Dasar. Jakarta: Prenadamedia Group.

Poerwanti, Endang. 2008. Asesmen Pembelajaran SD. Direktorat Jenderal Pendidikan Tinggi Departemen Pendidikan Nasional.

Wibowo, Mungin Eddy dkk. 2017. Tiga Pilar Konservasi: Penopang Rumah Ilmu Pengembang Peradaban Unggul. Semarang: Unnes Press. 